\title{
Meat Yield of the Strains Cobb 500, Hubbard Classic, Hubbard Flex, Hubbard 15 under Open and Close House Condition
}

\author{
N.M.T.S. Disanayaka ${ }^{1}$, M.A.J.P. Munasinghe ${ }^{1}$, R.M.A.S. \\ Bandara $^{1}$, L.A.N. Liyanage ${ }^{1}$ and P.D.C. Dissanayake ${ }^{2}$ \\ ${ }^{1}$ Department of Livestock Production, Faculty of Agricultural Sciences, \\ Sabaragamuwa University of Sri Lanka. thilinisadund@gmail.com \\ ${ }^{2}$ New Anthony’s Farm (Pvt) Ltd, Hanwella, Sri Lanka.
}

\begin{abstract}
Today Sri Lankan broiler industry has changed, selling of the whole carcass to separated carcass parts or deboned parts. In the processing industry there is a higher demand to gain the higher edible part, muscle yield and specially the breast muscle. The study was conducted to investigate the effect of strain and housing condition (open and close houses) to determine the meat yield of the broiler carcass. Hubbard Classic (HC), Hubbard Flex (HF), Hubbard 15 (H15) and Cobb 500 (C500) were the four commercial strains. At 38 days of their age, a total of 160 birds (40 birds from each strain / 80 birds from each housing condition) were randomly selected, slaughtered, eviscerated, weights were measured and dissected in to the separated parts (breast, thigh and drumstick). Weights of the body parts were recorded, deboned and the meat yield was measured. The research was designs by two factorial design. Data were statistically analyzed by using two-way Analysis of Variances (ANOVA) of SAS, 9 version. The birds that reared under the close houses showed the highest drumstick meatiness $(p<0.05)$. The ratio of the breast muscle weight to all other muscles, the meatiness of the thigh and breast were not significant affected from the housing condition. When considering the effect of the strain the HC has gained the overall superiority except the meatiness of the breast $(\mathrm{p}>0.05)$ and the thigh $(\mathrm{p}$ $<0.05$ ). The HF was resulted the highest ratio for it. Other four indicators the HC resulted the higher ratio over the other three strain $(\mathrm{p}<0.05)$. As a conclusion, it can be recommended to the industry, rearing of $\mathrm{HC}$ under closed house system to gain higher meat yield.
\end{abstract}

Keywords: Broilers, Closed houses, Meat yield, Open houses, Strain

\section{Introduction}

Ensminger (1992), defined that the Broiler, (Gallus gallusdomesticus) is 
young chicken (usually 6-8 weeks of age), that is tender meated and that has a soft pliable smooth textured skin and a flexible breast bone cartilage.

With the development of the industry, with many parties, there is a big competition to get higher profit. Broiler production and selling has changed its conception according to needs of customers and processing industry. Currently broiler production has commercialized by different ways. Few decades ago, the poultry products offer was mainly on whole carcass. Today it has changed to portioning carcass parts and de boning parts. Therefore, broiler producers are focused on the quality and higher yield of the major carcass parts with higher meatiness (breasts, thighs and drumsticks).

To gain higher profit, the major concept of the industry recognized increased the productivity of the broiler carcass. The genetic contribution of the broiler chicken as well as non-genetic factors such as age of slaughter, sex, nutrition and management practices are affected to birds performances. The researchers (Hossain et al., 2011); (Kurcubic et al., 2006); (Nikolova \& Pavlovski, 2009); (Marcato et al., 1920); (Shahin and Abdelazeem, 2005); (Shahin \& Elazeem, 2005) and (Traits et al., 2012) had shown the clear evidence that genetic and non-genetic factors affected the performances of the broilers.

The aim of this study was to determine the carcass yield of four different broiler strains Cobb 500, Hubbard Classic, Hubbard 15 and Hubbard Flex which reared under open and closed house conditions,

Obviously, the research focused to find out the best strain and the housing condition which gives the higher meat yield in Sri Lankan environment condition.

\section{Research methodology}

The research data collection was carried out at New Anthoney's farms (Pvt) Ltd processing plant in Tittapattara, Hanwella. A total of 160 broiler birds from four different strains were subjected in to the study. Hubbard Classic (HC), Hubbard Flex (HF), Hubbard 15 (H15) and Cobb 500 (C 500) were the 4 strains. Birds were reared closed house and open houses. All the birds were fed the formulated feed. They were slaughtered at 38 days of age.

Table 01: Sample selection of the research

\begin{tabular}{cccccccc}
\hline \multicolumn{3}{c}{ Closed house (80 birds) } & \multicolumn{4}{c}{ Open houses ( 80 birds $)$} \\
\hline C500 & HC & HF & H15 & C500 & HC & HF & H15 \\
20 & 20 & 20 & 20 & 20 & 20 & 20 & 20 \\
\hline
\end{tabular}


All the birds were selected at the receiving area of the processing plant, the digital balance (Mettle Toledo balance, Serial number is RIW06210-6BK) was used to measure the live weight of all the birds. They were labeled and hung on the automated processing line; the bleeding, scalding and de-feathering were done there. Then birds were separated from the automated line. Next, head and feet were removed, evisceration, portioning and deboning were done respectively and the length of the bones were measured manually.

The live weight, skin, fat, edible offal, neck, breast muscle, and all the muscles as well as head, wing tip, feet, bones and inedible offal were measured here. The length of keel, tibia and femur were measured at the end of the data collection. Calculations were done to determine the below mention indicators that determine the meat yield of broiler carcass. The edible parts include skin, fat, all the muscles and edible offal. Inedible parts include all the bones, head, feet, inedible offal, and wing tips. Edible offal includes liver, heart, gizzard, kidney and lungs, as well as the inedible offal includes crop, esophagus, proventriculus, inner thick layer of gizzard, gall bladder, spleen, testes, ovary, oviduct and respiratory track.

1. Ratio of edible parts to inedible $=$ Weight of edible part $(\mathrm{g}) /$ Weight of inedible part $(\mathrm{g})$

2. Ratio of edible parts to live weight $=$ Weight of edible part $(\mathrm{g}) /$ Live weight $(\mathrm{g})$

3. Ratio of muscle weight to the weight of bones = Weight of the muscle $(\mathrm{g}) /$ Weight of bones $(\mathrm{g})$

4. Ratio of (Breast, Thigh, Drumstick) muscle to all other muscles $=$ Weight of Breast muscle (g)/Weight of all other muscle (g)

Meatiness (Ratio of the weight of the muscle ( $\mathrm{g}$ ) to the length of its respective bones (cm)-Keel, Femur, Tibia

5. Beast meat weight/Length of keel

6. Thigh meat weight/Length of Tibia

7. Drumstick meat weight/Length of femur

All the weights were measured, indicators were calculated. Data was statistically analyzed by using SAS program 9 version using two way ANOVA. The research design was two factor factorial research design and mean separation was done by Turkey grouping method.

\section{Results and discussion}

In order to achieve the objectives, the weights were measured, and the ratios of seven indicators were calculated. The results which analyzed through the SAS pertaining to the experimental investigation are presented below. 


\section{Effect of the strain to the meatiness of the broiler chicken}

The average values of 4 ratios and 3 meatiness indicators for the four different strains are presented in the table 2.

Table 02: Average ratios and meatiness indicators of four broilers strains

\begin{tabular}{|c|c|c|c|c|c|}
\hline \multirow{2}{*}{ Indicators } & \multicolumn{5}{|c|}{ Strain } \\
\hline & C500 & $\mathrm{HC}$ & $\mathrm{HF}$ & H15 & $\mathrm{p}$ value \\
\hline $\begin{array}{l}\text { Ratio of Edible part / } \\
\text { Inedible parts }\end{array}$ & $1.20^{\mathrm{b}}$ & $1.24^{\mathrm{a}}$ & $1.17^{\mathrm{bc}}$ & $1.15^{\mathrm{c}}$ & $<0.001$ \\
\hline $\begin{array}{l}\text { Ratio of Edible part / } \\
\text { Live weight }\end{array}$ & $0.55^{\mathrm{b}}$ & $0.56^{\mathrm{a}}$ & $0.54^{\mathrm{b}}$ & $0.53^{\mathrm{b}}$ & $<.0001$ \\
\hline $\begin{array}{l}\text { Ratio of Muscle weight / } \\
\text { Bone weight }\end{array}$ & $1.56^{\mathrm{b}}$ & $1.76^{\mathrm{a}}$ & $1.63^{\mathrm{b}}$ & $1.61^{\mathrm{b}}$ & $<.0001$ \\
\hline $\begin{array}{l}\text { Ratio of Breast muscle weight / } \\
\text { All muscle weight }\end{array}$ & $0.54^{\mathrm{b}}$ & $0.62^{\mathrm{a}}$ & $0.49^{\mathrm{b}}$ & $0.50^{\mathrm{b}}$ & $<.0001$ \\
\hline $\begin{array}{l}\text { Meatiness of breast (Breast meat }(\mathrm{g}) / \\
\text { Length of the keel }(\mathrm{cm})\end{array}$ & $35.24^{\mathrm{a}}$ & $37.25^{\mathrm{a}}$ & $37.66^{\mathrm{a}}$ & $37.10^{\mathrm{a}}$ & 0.4850 \\
\hline $\begin{array}{l}\text { Meatiness of Drumstick (Drumstick } \\
\text { meat }(\mathrm{g}) / \text { Length of the Tibia }(\mathrm{cm})\end{array}$ & $50.26^{\mathrm{b}}$ & $59.37^{\mathrm{a}}$ & $48.23^{b}$ & $45.85^{b}$ & $<.0001$ \\
\hline $\begin{array}{l}\text { Meatiness of Thigh (Thigh meat }(\mathrm{g}) / \\
\text { Length of Femur }(\mathrm{cm})\end{array}$ & $10.32^{\mathrm{c}}$ & $13.57^{\mathrm{bc}}$ & $13.72^{\mathrm{a}}$ & $11.62^{b}$ & $<.0001$ \\
\hline
\end{tabular}

Different letters show statistically significant $(\mathrm{P}<0.05)$ differences among the treatments.

The ratio of edible part to inedible part, $\mathrm{HC}$ was resulted 1.24 highest average ratio when compare to the other three strains. The lowest ratio of the edible part to the inedible part 1.15 was resulted the strain H15. There is a significant effect of strain for the ratio of edible to inedible part of the broiler carcass $(\mathrm{p}<0.001)$.

The second ratio the edible parts to the live weight of the broilers resulted the significant effect with the four different strains $(p<0.0001)$. HC has gained the highest average ratio and it was 0.56 . The lowest value was resulted in H15 (0.53). The result shows that significant effect of the strain for the ratio of muscle weight to bone weight. HC was received the highest average ratio 1.76 ( $\mathrm{p}<0.0001)$, the C500 resulted the lowest (1.56). Comparing the ratio of breast muscle to all other muscle the highest average ratio was shown by strain HC (0.62) while HF resulted significantly lowest. 
When considering the meatiness of these three commercial carcass parts it was not resulted the significant effect of strain for the meatiness of breast ( $p$ $=0.485)$. When considering the meatiness of the drumstick it has significant effect on strain $(\mathrm{p}<0.0001)$. Further, $\mathrm{HC}$ received the highest average meatiness of drumstick; (59.37) and the lowest was in H 15, (45.85). Hubbard Flex was resulted the highest ratio of the meatiness of thigh (13.72) the lowest was resulted by C500 (10.32).

\section{Effect of the housing condition on the meatiness of the broiler chicken}

The ratios of seven indicators of the broiler birds in two housing conditions are presented in the table 3 . Out of 160 birds, 80 were reared under each housing system. The birds were in closed houses showed the highest values for all indicators except the meatiness of thigh; the value for the open house was 12.31 and the lowest in the closed house was 12.30. Four indicators shown the highest significant effect in close houses $(\mathrm{p}<0.05)$ when comparing to the open houses reared birds. The meatiness of thigh, breast and ratio of muscle weight to bone weight were not significantly affected $(\mathrm{p}<0.05)$ with regards to the housing condition. The ratio of edible part to the inedible parts; closed house reared birds was 1.21 significantly higher when comparing to the open house reared birds; 1.16 . The ratio of edible part to live weight in close house was 0.55 and the open houses 0.54 .

Table 03: Average ratios and meatiness indicators of their housing condition

\begin{tabular}{lccc}
\hline \multicolumn{1}{c}{ Indicators } & \multicolumn{3}{c}{ Effect of Strain } \\
\cline { 2 - 4 } & Open houses & Closed housed & p value \\
Ratio of Edible part / inedible parts & $1.16^{\mathrm{b}}$ & $1.21^{\mathrm{a}}$ & 0.0005 \\
Ratio of Edible part / live weight & $0.54^{\mathrm{b}}$ & $0.55^{\mathrm{a}}$ & $<.0001$ \\
$\begin{array}{l}\text { Ratio of Muscle weight / Bone weight } \\
\text { Ratio of Breast muscle weight / }\end{array}$ & $1.61^{\mathrm{a}}$ & $1.66^{\mathrm{a}}$ & 0.1178 \\
$\begin{array}{l}\text { all muscle weight } \\
\text { Meatiness of breast (Breast meat (g)/ }\end{array}$ & $0.49^{\mathrm{b}}$ & $0.68^{\mathrm{a}}$ & $<.0001$ \\
$\begin{array}{l}\text { Length of the keel(cm) } \\
\text { Meatiness of Drumstick (Drumstick } \\
\text { meat(g)/ Length of the Tibia (cm) }\end{array}$ & $34.07^{\mathrm{a}}$ & $39.56^{\mathrm{a}}$ & 0.485 \\
$\begin{array}{l}\text { Meatiness of Thigh (Thigh meat (g)/ } \\
\text { Length of Femur(cm) }\end{array}$ & $12.31^{\mathrm{a}}$ & $12.30^{\mathrm{b}}$ & 0.9970 \\
\hline
\end{tabular}

Different letters show statistically significant $(\mathrm{P}<0.05)$ differences among the treatments. 
According to the above results that significant effect of housing condition for the ratio muscle weight to bone weight 1.66 for closed house and lowest for open house was 1.61. The ratio of breast muscle to all other muscles, the highest average ratio 0.68 resulted by closed house reared birds. It was significantly higher comparing the open housed reared birds the value was 0.49. Meatiness of drumstick and breast higher in closed house the values were 52.54 and 39.56, the open houses resulted the values 49.31 and 34.07.

In this study resulted, the clear influence of the strain and the housing condition for the meat yield of the broiler chicken. It has proved the significant difference for the indicators by the four different strains. Among them $\mathrm{HC}$ resulted the superiority of overall performances, because $\mathrm{HC}$ resulted the significance superiority to the edible part to inedible part, ratio of edible part to live weight, ratio of breast muscle to all other muscle and the meatiness of the drumstick except the meatiness of the thigh, it had resulted the highest superiority by HF.

When considering the previous studies (Adebiyi and Adu, 2011); (Traits et al., 2012) (Hossain et al., 2011) and (Almasi et al., 2012) those were agreed that strain had significantly affected to the yield of the broiler production. It means the $\mathrm{HC}$ has more flesh, more edible part when comparing with inedible part, as well as the live weight and the bone weight. In commercially the most expensive muscle is pectorial major and the pectorial minor known as breast muscle. In this study it is higher in the HC comparing to all the muscles it also very important for the farmers to gain higher profit.

In Sri Lanka basically sell the whole carcass, but with time the broiler meat based processed products are very popular. To that the processor need to consider the meatiness of the carcass parts. So these indicators provide some parameters to compare the yield of the broiler and these parameters can be used for the further improvements in poultry breeding. The birds that reared under closed house has received the significant effect with meatiness except the ratio breast muscle to the bone weight, the meatiness of the thigh and the breast. The researchers (Kurcubic et al., 2006); (Hossain et al., 2011) and (Adebiyi and Adu 2011) also agreed with the current research that the housing condition affected to the performances of the broilers.

\section{Conclusion}

This study clearly reported that there is a significant relationship of the meat yield of the broiler by the strain and the housing condition. The strain HC was resulted the superiority of all meat ratios under the close house system. However the study proved clearly and can be recommended to the industry rearing of $\mathrm{HC}$ under closed house system to gain the higher meat yield, as well as it can be recommended the HC for boneless production. 


\section{References}

Adebiyi, O. \& Adu, O., 2011. Performance characteristics and carcass quality of broiler chicks under high stocking density fed vitamin E supplemented diet. Agriculture and Biology Journal of North America, 2(8), pp.11601165. Available at: http://www.scihub.org/ABJNA/PDF/2011/8/ ABJNA-2-8-1160-1165.pdf [Accessed July 8, 2014].

Almasi, A., Suto, Z. \& Budai, Z., 2012. Effect of age, sex and strain on growth , body composition and carcass characteristics of dual purpose type., pp.47-50.

Ensminger ,M. E,1992. Poultry Science .3 rd ed. Charbagh: International book distributing company

Hossain, M.A., Suvo, K.B. \& Islam, M.M., 2011. Fast- growing broiler strains raised under farming condition in bangladesh. , 1, pp.37-43.

Kurcubic, V., Petrovic, M.D. \& Radovic, V., 2006. The effect of sex and rearing system on carcass composition and cut yields of broiler chickens. , 2006(1), pp.31-38.

Marcato, S.M. et al., 1920. Growth of body parts of two broiler chicken strains.

Nikolova, N. \& Pavlovski, Z., 2009. Major carcass parts of broiler chicken from different genotype, sex , age and nutrition system. , 25, pp.10451054.

Shahin, K.A. \& Elazeem, F.A., 2005. Effects of breed, sex and diet and their interactions on carcass composition and tissue weight distribution of broiler chickens. , 48, pp.612-626.

Traits, P., Broiler, O.F. \& Strains, C., 2012. Production traits of broiler chicken strains fed ad libitum and raised on deep litter system in the humid tropics. , 9, pp.1529-1536. 
